This item was submitted to Loughborough's Institutional Repository (https://dspace.lboro.ac.uk/) by the author and is made available under the following Creative Commons Licence conditions.

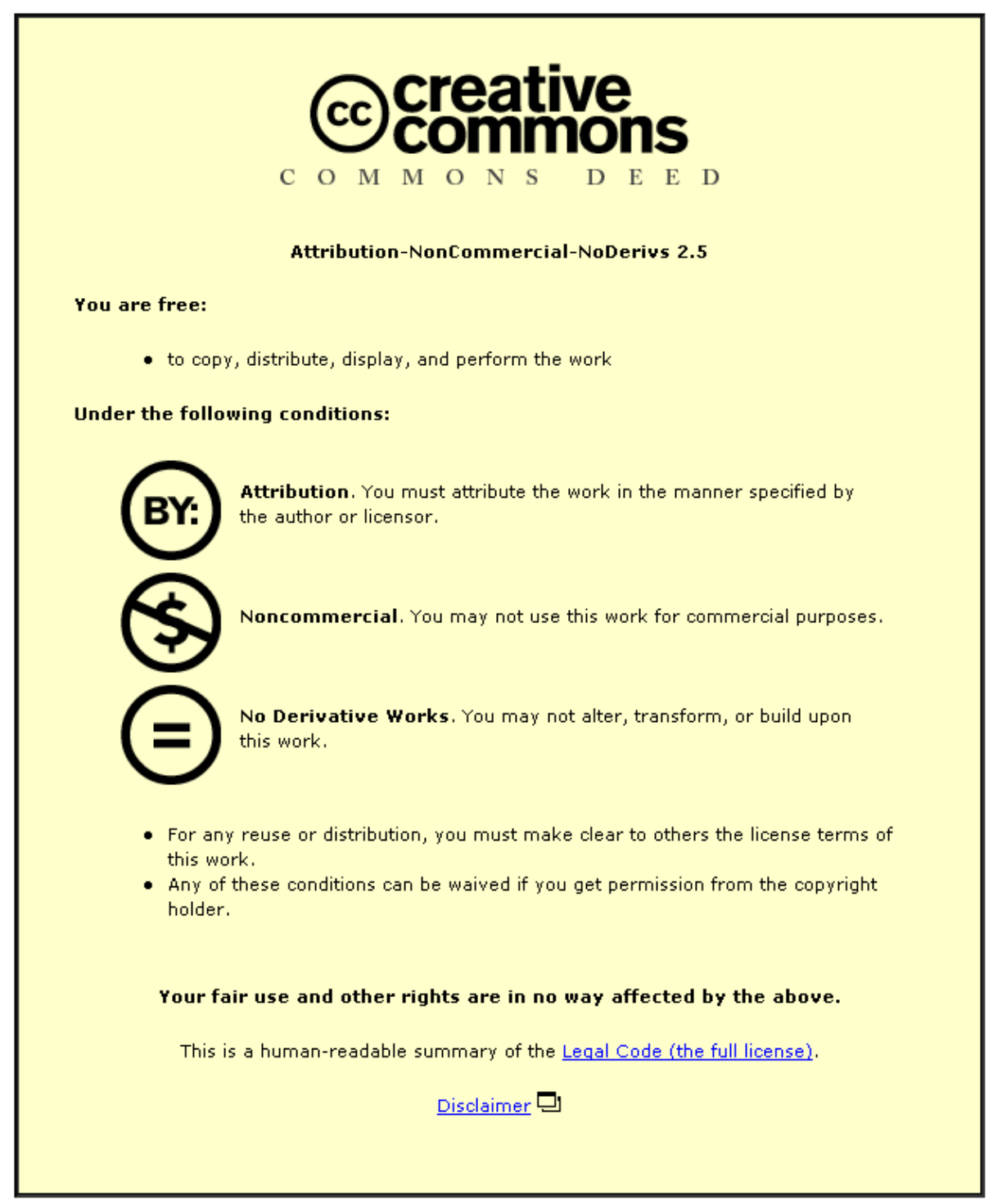

For the full text of this licence, please go to: http://creativecommons.org/licenses/by-nc-nd/2.5/ 


\title{
The effect of cylinder de-activation on thermo-friction characteristics of the connecting rod bearing in the New European Drive Cycle (NEDC)
}

\author{
Author, co-author (Mohammad pour M, Rahmani R, Rahnejat H)
}

Affiliation (Loughborough University)

Copyright @ 2014 SAE International

\begin{abstract}
This paper presents an investigation of Cylinder De-Activation (CDA) technology on the performance of big end bearings. A multi-physics approach is used in order to take into account more realistic dynamic loading effects on the tribological behavior. The power loss, minimum film thickness and maximum temperature of big end bearings have been calculated during maneuver pertaining to the New European Driving Cycle (NEDC). Results show that bearing efficiency runs contrary to efficiency gained through combustion and pumping losses. Under CDA mode, the power loss of big end bearings is more than the power loss under engine normal mode. The problem is predominant at higher engine speeds and higher Brake mean Effective Pressures (BMEP) in active cylinders. It is also observed that the minimum film thickness is reduced under the CDA mode. This can affect wear performance. In addition, same behavior is noted for the maximum temperature rise which is higher under CDA.
\end{abstract}

\section{Introduction}

The over-riding objective in modern engine development is fuel efficiency. This has led to a host of pursued measures, including down-sizing (a lower number of cylinders), high output power-to-weight ratio, variable valve activation or cylinder de-activation (CDA), as well as a gradual trend towards mild or micro-hybrid technology. Furthermore, the main aim is to use a suitable combination of the aforementioned methods with various driving conditions in order to reduce thermal and frictional losses as well as meeting the ever stringent emission directives as outlined in the NEDC. Another imperative is to ensure good NVH refinement which can be adversely affected by application of some of the above trends, such as light weight constructions [1] and exacerbated power torque variations with CDA. The highlighted issues affect the entire load bearing conjunctions in an engine. In particular, increased load fluctuations with CDA can also affect the big-end bearings.

CDA is seen as effective at low and partial engine loading conditions [2]. These conditions represent idling or low speed crawling in congested traffic, which progressively represent a greater proportion of everyday driving. The obvious benefit of CDA is fuel economy as the result of reduced pumping losses.
There are further benefits due to increased exhaust temperature under partial loading, yielding improved aftertreatment efficiency for diesel engines which helps the threeway calalyst technology $[3,4]$.

Engine order vibrations are the direct result of unbalanced inertial force and induced power torque which is a function of cylinder pressure [5]. When a cylinder is deactivated, all its intake and exhaust valves remain closed. This means that a volume of previously trapped air or the exhaust gas charge is retained within a deactivated cylinder. Therefore, cylinder-tocylinder pressure variation, exacerbated by CDA can lead to engine order vibration that would have been otherwise removed with the full engine operation through suitable cylinder phasing and firing order [5]. Therefore, the use of CDA is somewhat limited by the NVH refinement because of the resulting greater fluctuations in the output power torque [2, 6]. Douglas et al. [7] studied the effect of CDA mode in comparison with the normal engine mode during the NEDC cycle. A suitable region for the CDA operation was determined based on the BMEP. Results showed significant fuel improvement and emission reduction using the CDA technology.

To improve bearing stability, stiffness characteristics and load carrying capacity, the bearings are made in non-circular geometry (elliptic/lemon-shaped or multi-lobed), thus encouraging formation of multi-convergent wedges along the bearing periphery [8]. This action also reduces undue variations in the operating eccentricity, thus aiding bearing stability with increasing fluctuating loads in modern engines with a lower number of cylinders.

The first important aspect to take into account is the dynamic nature of big end bearing response under fluctuating loads. Bates et al [9] presented an experimental investigation and a theoretical model for dynamically loaded big end bearings. They neglected the effect of any distortion or lubricant cavitation. Conway-Jones et al [10] presented a numerical model for thermal analysis of big end bearings. They included the effect of bearing distortion through inclusion of bearing shell flexibility using finite element method. Aitken et al [11, 12] investigated dynamically loaded big end bearings, assuming elastohydrodynamic contact conditions. These conditions usually occur with overlay bearings where several layers of soft (low elastic modulus materials) are rolled upon the parent 
bearing bushing substrate in order to encourage localized deformation in the high pressure wedge region [13,14]. In fact, the pressures may be sufficient to deform the layers, but not usually of sufficient magnitude to induce piezo-viscous action of the lubricant itself. These conditions are often referred to as iso-viscous elastic or soft elastohydrodynamics [13]. A thin hard layer such as bismuth or indium is often coated on the overlay to resist wear of contacting surfaces when a thin film results, such as under start-up conditions or at low speeds [14]. Many analyses ignore the effect of overlay or the hard wear-resistant coating in the calculation of friction.

Other investigations of big end bearing dynamic response include the work of Boedo [15], who investigated film thickness and pressure distribution under dynamic oscillating conditions. Bonneau et al [16] also presented a numerical procedure, based on Newton-Raphson iterations. They included the structural deformation in an elastohydrodynamic analysis with the inclusion of lubricant cavitation. A multi-body dynamics approach, including the effect of soft overlay or thin shell construction, using the analytical column method approach for calculation of deformation was reported by Rahnejat [17] for a single cylinder engine for crankshaft circular bushing main support bearings under isothermal conditions. This approach was extended by Balakrishnan et al [14] for overlay crankshaft bearings, taking into account shear heating of the lubricant film. They included the effect of complex direct and moment loading with various cylinder firing in a compact 4-cylinder engine. It was shown that one repercussion of soft thermoelastohydrodynamics with low loads was the adverse journal stability. Another repercussion was thin films under heavy loads, resulting in direct interaction of the surfaces. Mohammadpour etal. [18] investigated the effect of CDA on big end bearings. They took into account the effect of system dynamics on the tribological properties at constant low speeds. Their results showed that unlike the general efficiency of engine, inefficiency in bearings due to frictional losses worsened with the application of CDA. The current work is an extension of that investigation for monitoring these effects in a more realistic driving cycle.

The current paper concentrates on the issues that affect the big-end bearing thermo-frictional characteristics during the NEDC cycle. The predictive approach, which is critical in multivariate problems of this kind includes the determination of regime of lubrication under fluctuating loads and frictional characteristics contributed by both elastohydrodynamics of the bearing overlay as well as boundary friction as the result of asperity interactions. Predictive results include applied dynamics, contact kinematics, frictional power loss, maximum lubricant temperature and minimum film thickness variations during the NEDC. The difference between the CDA mode and the normal operation mode (all active cylinders) has been investigated. These show that the general benefits accrued through fuel efficiency do not necessarily conform to improved big end bearing frictional efficiency.

\section{METHODOLOGY}

\section{Applied loads}

Big end bearings are subjected to transient applied loads as the result of the varying in-cycle piston kinematics (thus inertial Page 2 of 8 loading) and the combustion pressure. For a typical cylinder the inertial force along the axis of the piston is [5]:

$F_{\text {in }} \simeq m_{1} r_{c} \omega^{2}\left(\cos \omega t+\frac{r_{c}}{l} \cos 2 \omega t\right)$

where engine order vibrations up to the second engine order are considered for the 4-cylinder 4-stroke engine [5], and $m_{1}$ is the equivalent mass in translation, which is that of the piston, the gudgeon pin and a proportion of the mass of the connecting rod in pure translation, $m_{c o n}$. This is obtained by assuming the single cylinder geometry as a two degrees of freedom system; one in translation and the other in pure rotation. Hence: $m_{1}=m_{p}+m_{g}+m_{c o n}$, where [5]:

$m_{c o n}=\frac{W_{c o n}}{g}\left(1-\frac{C}{l}\right)$

where, $W_{\text {con }}$ is the weight of the connecting rod.

The applied combustion force on the big end bearing is obtained in terms of the instantaneous connecting rod obliguity angle as [5]:

$F_{\text {com }}=\frac{P_{c} A_{p}}{\cos \phi}$

where:

$\cos \phi \approx 1-\frac{r_{c}^{2}}{2 l^{2}} \sin ^{2} \omega t$

Therefore, the total load applied on the bearing is expressed as:

$F=\frac{F_{\text {in }}}{\cos \phi}+F_{\text {com }}$

This represents the maximum direct transient applied load which is carried by the big end bearing at any instant of time. There is also smaller moment loading contribution from the adjacent cylinders, ignored in the current analysis. A detailed bearing loading analysis is provided by Balakrishnan et al [14]. Ideally, the applied load is carried by a lubricant film formed in the journal-bushing conjunction (i.e. the elastohydrodynamic reaction). However, a coherent film of lubricant is not always assured due to the transient nature of engine operations (loadspeed combination as well as stop-start conditions). Hence, some of the applied load is carried by the direct contact of surfaces, usually a small portion of the rough topography of the crank-pin and the bushing surface (i.e. the asperities load share). The latter is usually overlaid with a sandwich of soft and hard layers which also deform locally as the result of conjunctional pressures, conditions which are referred to as soft elastohydrodynamic [13]. Therefore:

$W=\cos \varphi\left(W_{h}+W_{a}\right)=F$

where, $\varphi$ is the attitude angle. 
The elastohydrodynamic reaction is obtained as:

$W_{h}=\iint p(\theta, z) r d \theta d z$

The total asperity or boundary load for the bearing area is a function of surface roughness. For an assumed Gaussian distribution of asperities, according to Greenwood and Tripp [19]:

$W_{a}=\frac{16 \sqrt{2}}{15} \pi(\xi \beta \sigma)^{2} \sqrt{\frac{\sigma}{\beta}} E^{\prime} A F_{5 / 2}(\lambda)$

The statistical function $F_{5 / 2}(\lambda)$ is a function of Stribeck oil film parameter $\lambda=\frac{\mathrm{h}}{\sigma}$, where $\sigma$ is the composite root mean square roughness of the contiguous surfaces. More detail is presented in [20-21]. According to [19], the roughness parameter $\xi \beta \sigma$ is reasonably constant with a value in the range of 0.03 to 0.05 for steel surfaces. The ratio $\sigma / \beta$ is a representation of the average asperity slope [13] and is in the range $10^{-4}$ to $10^{-2}$ [19].

\section{Elastohydrodynamic conjunction}

\section{Generated lubricant pressures}

In order to obtain the hydrodynamic load carrying capacity in equation (7) the generated instantaneous pressure distribution in the bearing should be obtained using Reynolds equation:

$\frac{\partial}{\partial x}\left(\frac{h^{3}}{\eta} \frac{\partial p}{\partial x}\right)+\frac{\partial}{\partial z}\left(\frac{h^{3}}{\eta} \frac{\partial p}{\partial z}\right)=6\left(U \frac{\partial h}{\partial x}+V \frac{\partial h}{\partial z}+2 \frac{\partial h}{\partial t}\right)$

where: $U=\frac{1}{2} \omega r$ is the speed of lubricant entraining motion into the bearing conjunction in the circumferential direction $x$ (viewed as unwrapped: $x=r \theta$ ) and $V$ is the velocity of any side-leakage flow along the bearing's length, $z$ along the axis of the crank pin. The ultimate term on the right-hand side of the equation is lubricant entrapment in a dynamically converging gap, referred to as the squeeze film motion.

The conjunctional gap shape (i.e. film thickness, $h$ ) and the variation of lubricant dynamic viscosity $\eta$ are required for the solution of equation (9).

The boundary conditions, at the inlet wedge and the ends of the bearing are assumed to be: $p=0$. At the exit of the loaded region, the Reynolds boundary condition is used, therefore:

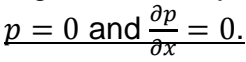

\section{Lubricant rheological state}

The lubricant viscosity increases with pressure and reduces with temperature. Its rise with pressure is a function of the product $\alpha p$ where $\alpha$ is its piezo-viscosity coefficient, which is $\alpha \simeq 10^{-8} \mathrm{~m}^{2} / \mathrm{N}$ for most engine oils. Pressures in the conforming contact of engine bearings are usually of the order of a few to tens of MPa. Thus, the product $\alpha p<<1$, and the conditions are considered to be iso-viscous. This equation Page 3 of 8 brings some approximations because of neglecting the piezoviscous effect effect which can be important in the case of highly loaded bearings. The effect of pressure on viscosity in the engine bearings is discussed in detail in [22]. In the current work the variation of lubricant viscosity with temperature is presented as [13]:

$\eta=\eta_{0} e^{-\beta_{0} \Delta T}$

where, $\eta_{0}$ is the lubricant dynamic viscosity at a given temperature, such as the bulk temperature at the bearing housing, $T_{0}$, and $\beta_{0}$ is the viscosity-temperature coefficient. $\Delta T$ is the rise in lubricant temperature from that in bulk.

\section{Conjunctional film shape}

Referring to figure 1, for an elliptic-bore journal bearing the film thickness $h$ is obtained as:

$h(\theta)=\frac{a b}{\sqrt{a^{2} \sin ^{2} \theta+b^{2} \cos ^{2} \theta}}-r-X \cos \theta-Y \sin \theta+\delta$

where, $0 \leq \theta \leq 2 \pi, a=r+c_{\min }$ and $b=r+c_{m a j}$ (Figure 1).

where $x$ and $y$ are the lateral excursions of journal centre from the geometric centre of the bearing bushing (radial eccentricities) at any instant of time:

$X=e_{0} \sin \varphi$ and $Y=-e_{0} \cos \varphi$

where $e_{0}$ is the eccentricity and $\varphi$ is the journal attitude angle relative to the vertical radial direction (Figure 1).

The term $\delta$ in equation (11) represents the deflection of the soft bearing bushing overlay. The conforming nature of journalbushing contact and the low elastic overlay, such as Babbitt ( $A$ Tin based alloy) or copper means that the local deflection of the bushing surface at any given location may be considered to be almost entirely due to an assumed column of local pressure directly orthogonal to it. Using the tri-axial state of stress-strain for a compressible shell material subjected to internal pressure and noting that for plane strain contact mechanics problems the compressive contact stress equates the localised pressure (i.e. the column method), Rahnejat [17] showed that:

$\delta=\frac{(1-2 v)(1+v) d}{E(1-v)} p$

where $d$ is the shell or overlay thickness (in this case the thickness of the soft Babbitt layer of the bushing overlay) and $E$ and $v$ are the Young's modulus of elasticity and Poisson ratio of the layer.

\section{Thermal analysis}

An analytical method based on a control volume approach described in Mohammadpour et al [18] is used in the current study to calculate the average temperature rise for the lubricant passage through the contact as well as the rise in the 
temperatures of the bounding surfaces; the journal and the bearing bushing.

Within the contact, the rate of heat generation through viscous shear of a film of lubricant is:

$\dot{Q}=\omega T_{f}$

where $T_{f}$ is the viscous friction torque:

$T_{f}=\int_{0}^{2 \pi} \int_{0}^{L} \tau r d \theta d z$

Note that the shear stress $\tau$ arises from hydrodynamic shear as well as asperity interactions[20]:

$\underline{\tau}=\tau_{h}+\tau_{b}$

where the hydrodynamic shear is:

$\underline{\tau_{h}}=\int \underline{ \pm} h \frac{d p}{d z}+\frac{\eta}{h} U$

and the boundary shear is [20]:

$\underline{\tau_{b}}=\tau_{L 0}+\gamma W_{a} / A_{a}$

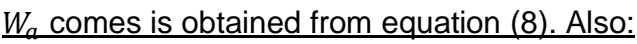

$\underline{A_{a}=\pi^{2}(\xi \beta \sigma)^{2} A F_{2}(\lambda)}$

$\tau_{L 0}$ and $\gamma$ are lubricant properties. $F_{2}(\lambda)$ is a statistical function of the Stribeck's oil film parameter $\lambda=\frac{h}{\sigma}$. Therefore, the asperity interaction is taken into account using these statistical methods and based on the operating conditions, lubricant and surface properties.

Part of the generated heat in the contact is dissipated through the bearing bushing, $\dot{Q}_{1}$ and the journal, $\dot{Q}_{2}$. The remainder is carried away by the lubricant through convection, $\dot{Q}_{c v}$. The film and surface temperatures can be obtained using the following heat balance (more detail is presented in [18]:

$\dot{Q}=\dot{Q}_{1}+\dot{Q}_{2}+\dot{Q}_{c v}$

\section{Friction in mixed regime of lubrication}

As already noted in the Introduction one key aim of any analysis of engine bearings is prediction of frictional power loss. In bearings, friction is mainly generated due to viscous shear of a lubricant film, entrained into the contact. Additionally, when the thickness of lubricant film is insufficient to completely separate the contacting surfaces, friction is also generated by interaction of rough features on the contiguous surfaces (boundary friction). Therefore, in mixed/boundary regime of lubrication, friction at the tip of asperities must be taken into account. The method presented in [18-20] has been used here in order to determine asperity friction.

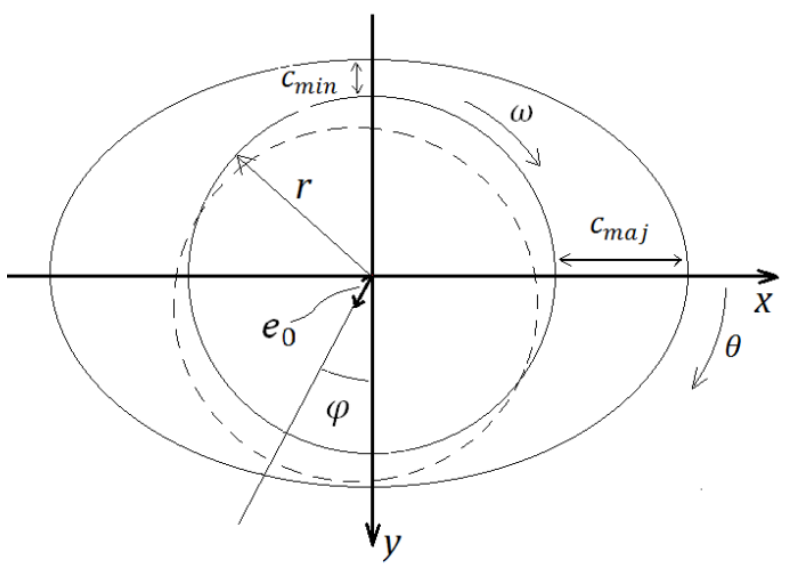

Figure 1: Elliptic bearing configuration

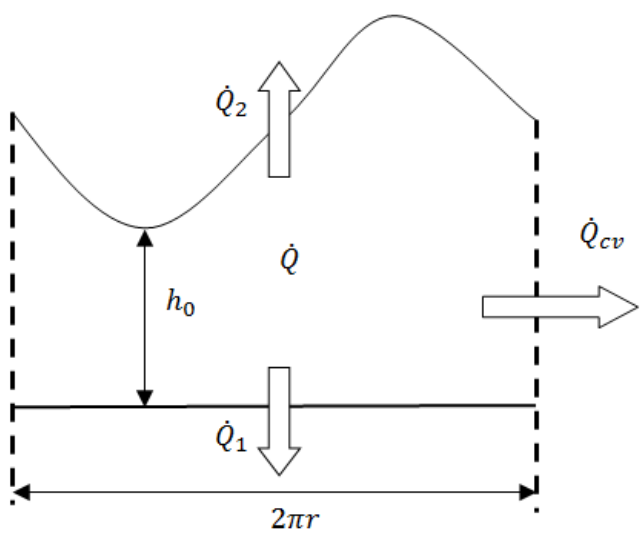

Figure 2: Thermal flow through the contact

\section{RESULTS AND DISCUSSION}

A C-class passenger car is used in the current analysis. Engine and vehicle data are the same as in [6]. Connecting rod data are presented in Table 1. Tables 2 and 3 present bearing and lubricant properties. A sweep of 400 second during NEDC is taken into account in order to monitor the bearing behavior. The cycle has been assumed at a warm surrounding temperature and the transient temperature rise through the NEDC full cycle is neglected. Therefore, the surrounding boundary temperature is assumed at the constant value of 80

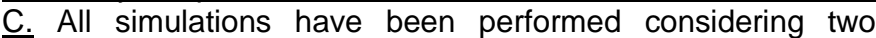
conditions: first the engine normal mode with all cylinders being active and second the CDA mode. In the CDA mode half of the cylinders are active at a higher pressure and the other half are deactivated with closed valves.

Table 1: Connecting rod data

\begin{tabular}{|l|c|}
\hline Parameter & Value \\
\hline Connecting rod length [mm] & 107.0 \\
\hline Effective translational mass [g] & 320.0 \\
\hline
\end{tabular}




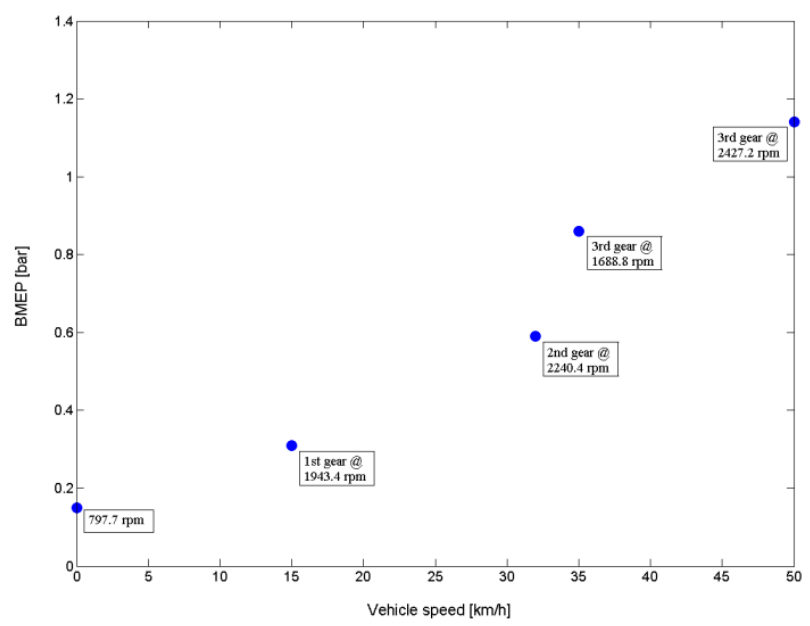

Figure 3: BEMP of normal model during acceleration

In order to obtain the combustion force, BMEP is required during acceleration. The BMEP for normal engine operating mode versus vehicle speed is presented in Figure 3 . In addition, equivalent engine speed and selected transmission speed are presented on the same figure for gear changing points. This figure shows that unlike vehicle speed which is always within the NEDC speed range (relatively high or relatively low); the engine speed progresses from $797 \mathrm{rpm}$ at idle to $2427 \mathrm{rpm}$ at the highest speed in the NEDC range. In this paper terms "high speed" and "low speed" refer to relatively high and relatively low speeds in the NEDC range. Conditions shown in figure 3 are taken from [7]. It should be noted that different transmission gears are active with different driving conditions. During the simulation process, the vehicle speed is taken from the NEDC at any point. Then, the engine rpm as well as BMEP are taken from the source data of figure 3 . Subsequently, the full applied load and bearing performance modeling can be performed.

Figure 4 presents the total power loss in the big-end bearings for the normal engine operating mode and that with the CDA. It shows that at lower speeds, the power loss for the normal engine mode and the CDA mode are very similar. However, at higher speeds with the bearing supporting a higher combustion loading, the power loss is $5 \%$ more in all the big end bearings. This contrary to the desired efficiency gains with CDA. However, the net value of this power loss is low in comparison with the efficiency improvements in engine combustion, but can be avoided using bearing design parameters such as supply pressure and preloading. By changing the preload factor, the load carrying capacity can be improved and lower elastohydrodynamic films can be partly avoided. Alternatively, the higher supply pressure can dissipate more thermal energy and reduce the film temperature which in turn would lead to thicker films and better hydrodynamic load carrying capacity. This approach may be used to reduce the lubricant viscous shear and thus reduce the ensuing power loss.

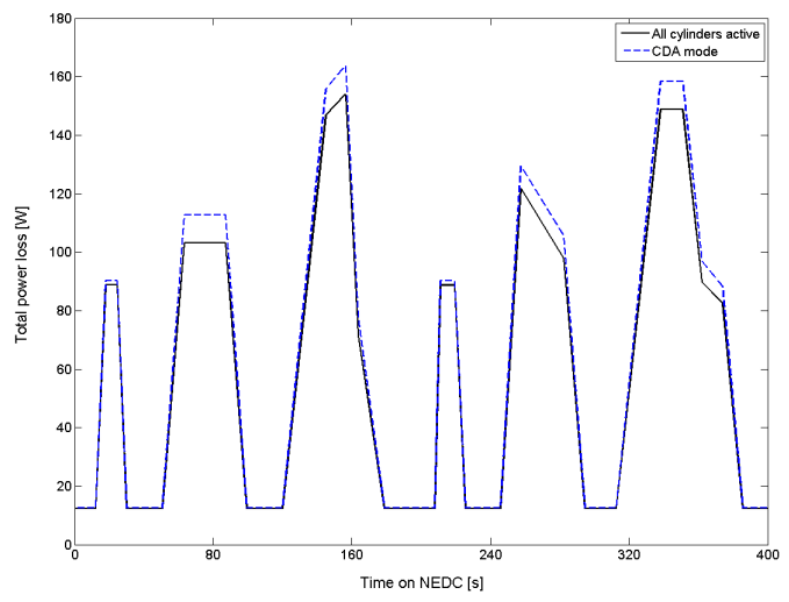

Figure 4: Power loss during NEDC

Table 2: Lubricant properties

\begin{tabular}{|l|l|}
\hline Parameter & Value \\
\hline Lubricant dynamic viscosity [mPa.s] & 8.0 \\
\hline Lubricant density [Kgm-3] & 833.8 \\
\hline Viscosity-temperature coefficient [K-1] & 0.026 \\
\hline Pressure-induced shear coefficient $(\gamma)$ & 0.047 \\
\hline Atmospheric limiting shear stress [MPa] & 2.3 \\
\hline Specific heat capacity of lubricant [Jkg-1K-1] & 2360 \\
\hline Thermal conductivity of lubricant [Wm-1K-1] & 0.225 \\
\hline Poison's ratio for Babbitt [-] & 0.33 \\
\hline Young's modulus for Babbitt [GPa] & 60 \\
\hline Thermal conductivity of bearing bushing $\mathrm{k}_{\mathrm{s} 1}[\mathrm{Wm}-1 \mathrm{~K}-1]$ & 46 \\
\hline Thermal conductivity of journal $\mathrm{k}_{\mathrm{s} 2}[\mathrm{Wm}-1 \mathrm{~K}-1]$ & 25.96 \\
\hline Ambient oil temperature [ $\left.{ }^{\circ} \mathrm{C}\right]$ & 80 \\
\hline Journal material & $\mathrm{SG}$ cast iron \\
\hline Bearing overlay & Babbitt \\
\hline Eyring shear stress [MPa] & 5 \\
\hline Inlet pressure [MPa] & 0.5 \\
\hline
\end{tabular}

Table3: Bearing properties

\begin{tabular}{|l|l|}
\hline Parameter & Value \\
\hline Bearing width $[\mathrm{mm}]$ & 16.8 \\
\hline Bearing radius $[\mathrm{mm}]$ & 21.0 \\
\hline Minor diametral clearance $[\mu \mathrm{m}]$ & 20.0 \\
\hline Major diametral clearance $[\mu \mathrm{m}]$ & 30.0 \\
\hline Composite surface roughness $[\mu \mathrm{m}]$ & 1 \\
\hline Shell thickness value $[\mathrm{mm}]$ & 2.6 \\
\hline
\end{tabular}




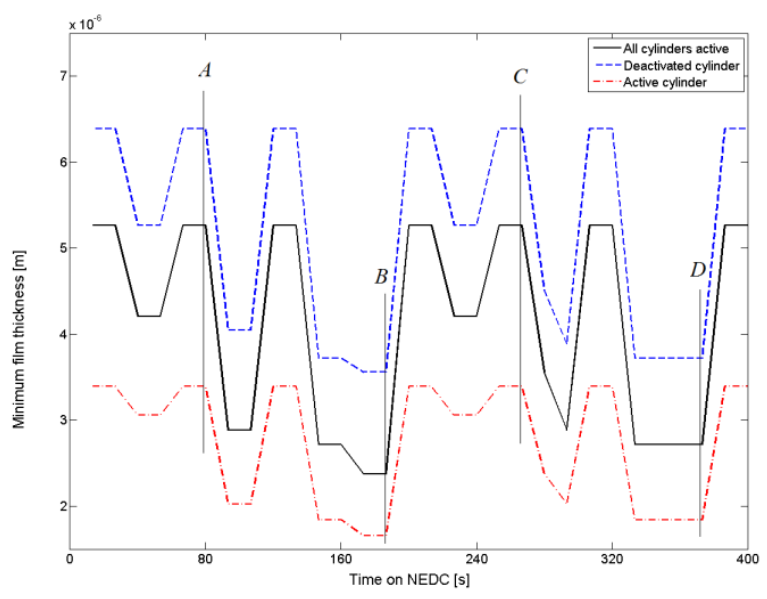

Figure 5: Minimum film thickness during NEDC

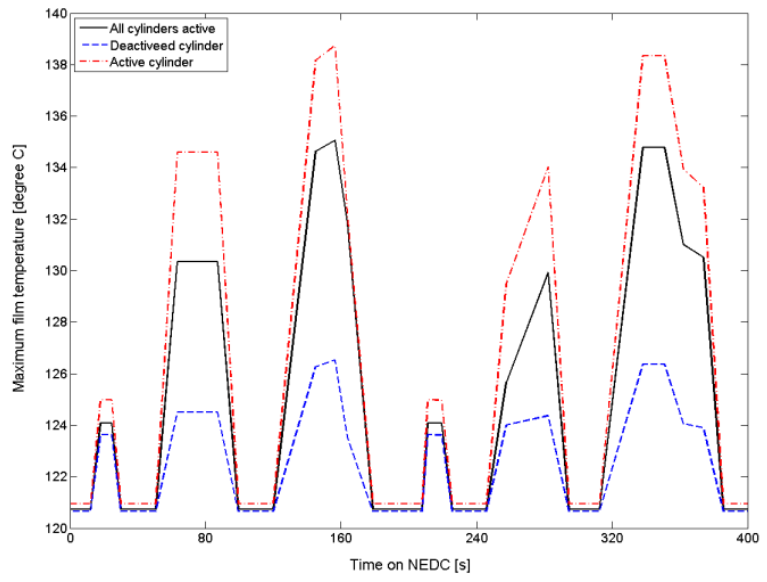

Figure 6: Maximum film temperature of bearing during NEDC

Figure 5 shows the minimum film thickness for the big end bearings. They are presented for both normal and the CDA modes. It shows that the film thickness in the active cylinders, which are subjected to the highest pressure loading is quite low in comparison with that under the normal engine mode. The minimum value in this case study is around $1 \mu \mathrm{m}$. Therefore, the conditions are those of mixed regime of lubrication. This is one of reason for a greater frictional power loss due to asperity interactions. Another impact of this low film thickness can be wear and durability of bearings under the CDA mode.

Table 4 provides the boundary friction torques at the points $A$, $B, C$ and $D$ in figure 5 . These results show that the higher power loss (figure 4) happens with the thinner film thickness (figure 5) and presents a greater incidence of asperity friction.

Table 5 provides the maximum pressure values at points $A, B$, $\mathrm{C}$ and $\mathrm{D}$ in figure 5 . These results show that the pressure value may exceed $100 \mathrm{MPa}$ in the active cylinder. This result is in line with the values in [22]. Therefore, in a future study the

Page 6 of 8 piezo-viscous action leading to increased viscosity should be taken into account at relatively high applied loads.

Table4: Boundary friction torque for different points on the figure 3

\begin{tabular}{|l|l|l|l|l|}
\hline Point & A & B & C & D \\
\hline $\begin{array}{l}\text { Boundary friction torque in } \\
\text { active cylinder [Nm] }\end{array}$ & 0 & 0.3325 & 0 & 0.3294 \\
\hline $\begin{array}{l}\text { Boundary friction torque in } \\
\text { deactivated cylinder [Nm] }\end{array}$ & 0 & 0 & 0 & 0 \\
\hline $\begin{array}{l}\text { Boundary friction torque in all } \\
\text { cylinders active mode [Nm] }\end{array}$ & 0 & 0.2803 & 0 & 0.2428 \\
\hline
\end{tabular}

Table5: Maximum pressure values for different points on the figure 3

\begin{tabular}{|l|l|l|l|l|}
\hline Point & A & B & C & D \\
\hline $\begin{array}{l}\text { Maximum pressure in active } \\
\text { cylinder [MPa] }\end{array}$ & 19.81 & 130.64 & 19.81 & 120.79 \\
\hline $\begin{array}{l}\text { Maximum pressure in } \\
\text { deactivated cylinder [MPa] }\end{array}$ & 4.48 & 38.89 & 4.48 & 28.86 \\
\hline $\begin{array}{l}\text { Maximum pressure in all } \\
\text { cylinders active mode [MPa] }\end{array}$ & 7.07 & 65.53 & 7.07 & 51.6 \\
\hline
\end{tabular}

Figure 6 shows the maximum lubricant temperature for the normal engine operation mode as well as with the CDA for both active and deactivated cylinders. These follow the power loss. At lower speeds the temperature rise is close to the engine normal operation mode. However, at higher speeds, the CDA mode shows a $40 \%$ temperature rise. This finding is in line with observed practice and remains a source of concern for the application of CDA.

\section{Summary/Conclusions}

The paper presents a multi-physics model including dynamics and tribology of big end bearings. The effect of CDA technology has been studied on the big end bearing as one of the components, affected by the use of CDA. The results show that unlike improvements in fuel usage and reduced accessory losses, the bearing power loss worsens in the CDA mode. This can be explained through the generation of thinner lubricant films due to higher load in active cylinders. In addition, two pressurized region in deactivated cylinders (double the combustion frequency) causes two region of smaller film thickness leading to regions of increased shear. Therefore, generally higher hydrodynamic shear as well as more asperity interactions occurs with CDA technology. However, the net value of this power loss is quite low in comparison with the efficiency improvements in engine combustions with the CDA. However, the same trends may also occur in other engine load bearing conjunctions as well, such as in the piston assembly. Therefore, in-depth analyses such as that described here should form part of the engineering process. In addition to the frictional power loss, other design 
concerns such as shaft bending and misalignment should also be investigated in future research. The predicted losses can be avoided by redesigning the conjunctional components based on the new CDA technology. For example, by changing the preload factor, the load carrying capacity can be improved and thinner films can be partly avoided. Higher supply pressures may also dissipate some of the generated thermal energy, thus reducing the film temperature, enhance viscosity and load carrying capacity. These in turn would reduce viscous shear and friction as well as reducing the chance of boundary interactions.

\section{References}

1. Kushwaha, M., Gupta, S., Kelly, P. and Rahnejat, H., "Elasto-multi-body dynamics of a multicylinder internal combustion engine", Proc. IMechE, J. Multibody Dynamics, 216(4), 2002, pp. 281-293

2. Falkowski, A., McElwee, M., and Bonne, M., "Design and Development of the DaimlerChrysler 5.7L HEMI ${ }^{\circledR}$ Engine Multi-Displacement Cylinder Deactivation System," SAE Technical Paper 2004 01-2106, 2004, doi: 10.4271/2004-01-2106.

3. Roberts, C., "Variable Valve Timing," SwRI Project No. 03.03271, Clean Diesel III Program, March 2004.

4. Wilcutts, M., Switkes, J., Shost, M., and Tripathi, A., "Design and Benefits of Dynamic Skip Fire Strategies for Cylinder Deactivated Engines," SAE Int., J. Engines 6(1), 2013, pp. 278-288, 2013, doi:10.4271/2013-01-0359.

5. Rahnejat, H., Multi-body Dynamics: Vehicles, Machines and Mechanisms, Joint publishers: Professional Engineering Publishing (UK) and SAE (USA), 1998, ISBN: 0-7680-0269-9

6. Senapati, U., McDevitt, I., and Hankinson, A., "Vehicle Refinement Challenges for a Large Displacement Engine with Cylinder Deactivation Capability," SAE Technical Paper 2011-01-1678, 2011, doi:10.4271/2011-01-1678.

7. Douglas K. J., Milovanovic N., Turner J. W. G. and Blundell D. " Fuel Economy Improvement Using Combined CAI and Cylinder Deactivation (CDA) An Initial Study" 2005 SAE World Congress (2005).

8. Mishra, P.C. and Rahnejat, H., "Tribology of big end bearings" in Rahnejat, $\mathrm{H}$ (Ed.), Tribology and dynamics of engine and power train, Woodhead Publishing, Cambridge, UK, 2010 ISBN: 978-184569-361-9

9. Bates, T. W., Fantino, B., Launay, L., Frěne, J., "Oil film thickness in an elastic connecting-rod bearing: comparison between theory and experiment", Tribology Transactions 33(2), 1990: pp. 254-266.

10. Conway-Jones, J. M., F. A. Martin, and R. Gojon. "Refinement of engine bearing design techniques", Tribology International, 24 (2), 1991, pp. 119-127

11. Aitken, M. B., and H. McCallion. "Elastohydrodynamic Lubrication of Big-End Bearings Part 1: Theory", Proc. Instn. Mech. Engrs., Part C: J. Mechanical Engineering Science 205(2), 1991, pp. 99-106.

12. Aitken, M. B., and H. McCallion. "Elastohydrodynamic Lubrication of Big-End Bearings Part 2: Ratification", Proc. Instn. Mech. Engrs., Part C: J. Mechanical Engineering Science 205(2), 1991, pp. 107-119

13. Gohar, R. and Rahnejat, H., Fundamentals of Tribology, Imperial College Press, London, 2008, ISBN-13 978-1-84816-184-9

14. Balakrishnan, S., McMinn, C., Baker, C.E. and Rahnejat, H., "Fundamentals of crank and camshaft support journal bearings", in Rahnejat, H. (Ed.), Tribology and dynamics of engine and powertrain, Woodhead Publishing, Cambridge, UK, 2010, ISBN: 978-1-84569-361-9

15. Boedo, S., "Practical tribological issues in big-end bearings", in Rahnejat (ed.), Tribology and Dynamics of Engine and Powertrain, Woodhead Publishing, Cambridge, UK, ISBN: 978-1-84569-361-9 .

16. Bonneau, D., Guines, D., Frene, J. and Toplosky, J., "EHD analysis, including structural inertia effects and a mass-conserving cavitation model" Trans. ASME, J. Tribology, 117(3), 1995, pp. 540-547.

17. Rahnejat, H., "Multi-body dynamics: historical evolution and application", Proc. Instn. Mech. Engrs., Part C: J. Mechanical Engineering. Science, 214(1), 2000, pp. 149-173

18. Mohammadpour M., Rahmani, R., Rahnejat H. " Effect of cylinder deactivation on the tribo-dynamics and acoustic emission of overlay big end bearings ." Proceedings of the Institution of Mechanical Engineers, Part K: Journal of Multi-body Dynamics (2013).

19. Greenwood, J. A. and Tripp, J. H., "The contact of two nominally flat rough surfaces", Proc. Instn. Mech. Engrs, 185, 1970-71, pp. 625-633

20. Teodorescu, M., Balakrishnan, S. and Rahnejat, H., "Integrated tribological analysis within a multiphysics approach to system dynamics", Tribology and Interface Engineering Series, 48, 2005, pp. 725737 
21. Mohammadpour M., Theodossiades S., Rahnejat H., and Kelly P. "Transmission efficiency and noise, vibration and harshness refinement of differential hypoid gear pairs." Proceedings of the Institution of Mechanical Engineers, Part K: Journal of Multi-body Dynamics, 2013, doi: 10.1177/1464419313496559

22. Allmaier, H., et al. "Predicting friction reliably and accurately in journal bearings-The importance of extensive oil-models." Tribology International 48 (2012): 93-101.

\section{Contact Information}

Mahdi Mohammadpour Wolfson School of Mechanical and Manufacturing Engineering Loughborough University Loughborough, Leicestershire, LE11 3TU, United Kingdom

Email:m.mohammad-pour@lboro.ac.uk

\section{Definitions/Abbreviations}

$\begin{array}{ll}\mathrm{A} & \text { Apparent contact area } \\ \mathrm{A}_{\mathrm{p}} & \text { Piston cross-sectional area } \\ \mathrm{A}_{\mathrm{a}} & \text { Total asperity contact area } \\ a, b & \text { Measures along the semi-major and semi- } \\ \text { minor directions of elliptic bore } \\ \mathrm{C} & \text { Centre of mass of the connecting rod } \\ \mathrm{c}_{\mathrm{maj}} & \text { Contact clearance along the semi-major axis } \\ \mathrm{c}_{\mathrm{min}} & \text { Contact clearance along the semi-minor axis } \\ \mathrm{d} & \text { Shell (overlay) thickness } \\ \mathrm{E} & \text { Young's modulus of elasticity } \\ \mathrm{E}^{\prime} & \text { Composite Young's modulus of elasticity of }\end{array}$
contacting solids

$\mathrm{e}_{0}$
$\mathrm{~F}_{5 / 2}$
$\mathrm{~F}_{\text {com }}$
$\mathrm{F}_{\text {in }}$
$\mathrm{g}$
$\mathrm{h}$
$\mathrm{L}$
$\mathrm{l}$
$\mathrm{m}_{1}$
$\mathrm{~m}_{\text {con }}$
connecting rod
$\mathrm{m}_{\mathrm{g}}$
$\mathrm{m}_{\mathrm{p}}$

$$
\left(\frac{1}{\mathrm{E}^{\prime}}=\frac{1-v_{1}^{2}}{\mathrm{E}_{1}}+\frac{1-v_{2}^{2}}{\mathrm{E}_{2}}\right)
$$$$
\text { Eccentricity }
$$$$
\text { Statistical functions }
$$$$
\text { Combustion gas force }
$$$$
\text { Inertial force }
$$$$
\text { Gravitational acceleration }
$$$$
\text { Film thickness }
$$$$
\text { Bearing width }
$$$$
\text { Connecting rod length }
$$$$
\text { Effective mass in translational motion }
$$$$
\text { Equivalent translational mass of the }
$$

Gudgeon pin mass

Piston mass

\begin{tabular}{|c|c|}
\hline$P_{c}$ & Combustion gas pressure \\
\hline $\mathrm{p}$ & Hydrodynamic pressure \\
\hline$\dot{\mathrm{Q}}$ & Heat transfer (or generation) rate \\
\hline$\dot{\mathrm{Q}}_{1}$ & Heat transfer rate to the bearing bushing \\
\hline$\dot{\mathrm{Q}}_{2}$ & Heat transfer rate to the journal \\
\hline$\dot{\mathrm{Q}}_{\mathrm{cv}}$ & Convection heat transfer rate \\
\hline $\mathrm{r}$ & Journal radius \\
\hline $\mathrm{r}_{\mathrm{c}}$ & Crank pin radius \\
\hline $\mathrm{T}$ & Temperature \\
\hline $\mathrm{T}_{0}$ & $\begin{array}{l}\text { Inlet temperature of the lubricant into the } \\
\text { contact (also bulk housing temperature) }\end{array}$ \\
\hline $\mathrm{T}_{\mathrm{f}}$ & Friction induced torque \\
\hline $\mathrm{t}$ & Time \\
\hline $\mathrm{U}$ & Speed of lubricant entraining motion \\
\hline $\begin{array}{l}\mathrm{V} \\
\text { bearing width }\end{array}$ & Velocity of side-leakage flow along the \\
\hline & Contact reaction \\
\hline$W_{c o n}$ & Total weight of the connecting rod \\
\hline $\mathrm{W}_{\mathrm{a}}$ & Load carried by asperities \\
\hline $\mathrm{W}_{\mathrm{h}}$ & Hydrodynamic load carrying capacity \\
\hline $\mathrm{X}, \mathrm{Y}$ & Lateral radial co-ordinates \\
\hline $\mathrm{x}$ & unwrapped coordinate of bearing: $x=r \theta$ \\
\hline $\mathrm{z}$ & Axial direction along the bearing width \\
\hline \multicolumn{2}{|c|}{ Greek symbols } \\
\hline$\alpha$ & Pressure viscosity of the lubricant \\
\hline$\beta$ & Average asperity tip radius \\
\hline$\beta_{0}$ & Viscosity-temperature coefficient \\
\hline$\gamma$ & Non0newtonian shear slope \\
\hline$\delta$ & Local elastic deflection \\
\hline $\begin{array}{l}\theta \\
\text { bearing }\end{array}$ & Crank angle and circumferential direction in \\
\hline$\eta$ & Lubricant dynamic viscosity \\
\hline $\begin{array}{l}\eta_{0} \\
\text { conditions }\end{array}$ & Lubricant dynamic viscosity at ambient \\
\hline$\lambda$ & Stribeck's oil film parameter \\
\hline$v$ & Poisson's ratio \\
\hline$\xi$ & Asperity density per unit area \\
\hline$\sigma$ & Composite RMS surface roughness $(\sigma=$ \\
\hline \multicolumn{2}{|l|}{$\left.\sqrt{\sigma_{1}^{2}+\sigma_{2}^{2}}\right)$} \\
\hline$\tau$ & Shear stress \\
\hline$\tau_{h}$ & Hydrodynamic shear stress \\
\hline$\tau_{b}$ & Boundary shear stress \\
\hline$\tau_{L 0}$ & Eyring stress \\
\hline$\phi$ & Connecting obliguity angle \\
\hline$\varphi$ & Journal attitude angle \\
\hline$\omega$ & Angular speed of crank shaft (engine speed) \\
\hline \multicolumn{2}{|l|}{ Abbreviations } \\
\hline CDA & linder Deactivation \\
\hline $\mathrm{NVH}$ & Noise, Vibration and Harshness \\
\hline BMEP & Brake Mean Effective Pressure \\
\hline
\end{tabular}

